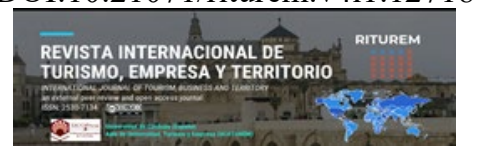

Cita bibliográfica: Mendoza, I. y Alcívar, G.L. (2020). La zonificación territorial como instrumento de planificación y gestion de destinos turísticos afectados por desastres naturales: la estrategia posterremoto de 2016 en Portoviejo (Ecuador). Revista Internacional de Turismo, Empresa y Territorio, 4 (1), 1-21. https://doi.org/10.21071/riturem.v4i1.12718

\title{
La zonificación territorial como instrumento de planificación y gestión de destinos turísticos afectados por desastres naturales: la estrategia posterremoto de 2016 en Portoviejo (Ecuador)
}

\author{
Territorial zoning as an instrument for planning and managing tourist destinations \\ affected by natural disasters: the 2016 post-earthquake strategy in Portoviejo (Ecuador)
}

\author{
Iván Mendoza Montesdeoca ${ }^{*}$ \\ Gema Leonela Alcívar Cabrera ${ }^{2}$
}

\begin{abstract}
Resumen
Esta investigación pretende demostrar cómo la utilización de la técnica de zonificación en la planificación urbana puede contribuir a la recuperación de los sistemas de gestión turística y comercial en ciudades afectadas por desastres naturales como este caso de Portoviejo, tras haber atravesado por un sismo de $7,8^{\circ}$ en la escala de Richter en 2016. Este trabajo utiliza un enfoque exploratorio descriptivo diseñado en dos fases clave: la primera, en la que se realizó un diagnóstico turístico integral, y la segunda, en la que se levantó una planimetría georreferenciada en la que se representó el estado del sistema socioeconómico y ambiental de la ciudad por barrios y distritos. Entre los resultados obtenidos destaca el fuerte impacto sufrido en la economía local por el desastre natural y la factibilidad positiva para la ejecución de una zonificación turística a partir del Plan de Ordenación Territorial cantonal. Se procedió para ello una evaluación de los distintos sectores urbanos de la ciudad desde el punto de vista socio ambiental y económico hasta distinguir cuatro zonas principales: zona de mayor sostenibilidad; turística; residencial; comercial y empresarial. Se concluye con la confirmación de que el diseño de una zonificación territorial constituye una buena herramienta para la ordenación y planificación turística del territorio y la eficiencia de su sistema de gobernanza, con el objeto de fomentar el desarrollo sostenible y la recuperación de destinos afectados por este tipo desastres.
\end{abstract}

Palabras clave: recuperación destinos turísticos urbanos; desastres socionaturales; desarrollo sostenible; zonificación turística; ordenamiento territorial.

\begin{abstract}
This research aims to demonstrate how the use of the zoning technique in urban planning can contribute to the recovery of tourism and commercial management systems in cities affected by natural disasters

\footnotetext{
${ }^{1}$ Escuela Politécnica Agropecuaria Superior de Manabí (ESPAM), Ecuador. mendozaivan86@gmail.com. Id orcid: 0000-0001-7632-144X. * Autor para la correspondencia

${ }^{2}$ Escuela Politécnica Agropecuaria Superior de Manabí (ESPAM), Ecuador. Ingeniera en Turismo.
} 
such as this case of Portoviejo, after having suffered an earthquake of $7.8^{\circ}$ on the Richter scale in 2016. This work uses a descriptive exploratory approach designed in two key phases: the first, in which a comprehensive tourist diagnosis was made, and the second, in which a georeferenced planimetry was created in which it represented the state of the city's socioeconomic and environmental system by neighborhoods and districts. Among the results obtained, the strong impact suffered on the local economy by the natural disaster and the positive feasibility for the execution of a tourist zoning based on the Cantonal Territorial Planning. For this, an evaluation of the different urban sectors of the city was carried out from the socio-environmental and economic point of view, until four main areas were distinguished: the area with the greatest sustainability; tour; residential; commercial and business. It concludes with the confirmation that the design of a territorial zoning constitutes a good tool for the tourist planning and organization of the territory and the efficiency of its governance system, in order to promote sustainable development and the recovery of destinations affected by it disaster type.

Keywords: recovery of urban tourist destinations; socio-natural disasters; sustainable development; tourist zoning; territorial planning.

\section{Introducción}

El turismo sigue siendo en la actualidad una de las actividades económicas con más capacidad de crecimiento, dinamismo empresarial y generación de desarrollo tanto a nivel nacional como internacional, como así atestiguan los datos más recientes de la Organización Mundial del Turismo OMT (2019). Este efecto importante de aceleración del desarrollo económico y del fenómeno de la globalización a nivel mundial que se atribuye al turismo no sólo se detecta en los países occidentales más desarrollados de América del Norte, Europa y algunos países asiáticos, sino que se extiende también con carácter general a otros muchos países pobres o en vías de desarrollo (en adelante PPVD) (Sun, Tang y Zhang, 2011), que además están experimentando desde hace décadas importantes fuertes concentraciones de población en sus principales ciudades, fruto del fenómeno del éxodo rural y las migraciones descontroladas hacia estos núcleos urbanos con mayores oportunidades de empleo. Y, a su vez, estas grandes aglomeraciones urbanas en muchos casos se convierten igualmente en los principales focos de atracción turística tanto del turismo nacional como internacional, lo que exige la puesta en marcha de una planificación territorial y sectorial -entre ellas la turística- ciertamente compleja en estas urbes (Wu, Han, y Lai, 2009).

La gestión del crecimiento urbano es, sin duda, un tema de gran importancia y recurrencia en nuestro mundo contemporáneo debido al rápido desarrollismo económico y los procesos imparables de urbanización desordenada y a ves caótica iniciados en las ciudades occidentales tras la Segunda Guerra Mundial y hoy día generalizados a nivel mundial (Sheridan, 2007), que causan numerosos problemas como el deterioro del medio ambiente, el uso ineficiente del suelo disponible, los conflictos sociales y de segregación socioeconómica o el desbordamiento e incapacidad de los gobiernos locales a la hora de atender las demandas de crecimiento exponencial de servicios públicos y asistenciales y de equipamientos urbanos de todo tipo (Carruthers y Ulfarsson, 2003; Freeman, 2007; Ewing, Pendall, y Chen, 2010; Liu, Liu y Qiu, 2013; Elbeih, Shalaby y Deen, 2013;). Estos problemas presentan una gran amenaza para la sostenibilidad urbana, lo que ha llevado a muchos especialistas a intentar aplicar nuevas teorías de urbanismo y prácticas y métodos en materia de ordenación territorial de grandes áreas metropolitanas y aglomeraciones urbanas (Smith, 2002; Filion y McSpurren, 2007), tanto en Europa como ampliamente también en Norte América y Japón, donde han estado dirigidas hacia la gestión del crecimiento urbano y el control y ordenación de la expansión urbana para conseguir un desarrollo menos intensivo y desordenado (Martin, Pendall y Fulton, 2002; Munton, 1983; Sorensen, 2003) y en línea con los Objetivos de Desarrollo Sostenible (ODS) (Rivera, 2020). 
En el caso de países de América del Sur como Ecuador se ha considerado con frecuencia y hasta sobrevalorado la inversión privada en el sector del turismo como una efectiva alternativa socioeconómica, como instrumento de generación de empleo y un sector de actividad fuertemente dinamizador de la economía en toda su cadena de valor. Sin embargo, esta visión no ha ido acompañada de una auténtica o al menos sustantiva planificación estratégica y de activación sostenible de la puesta en valor del patrimonio natural y cultural de los territorios. El turismo en Ecuador se ha convertido, en cualquier caso, en una de las principales actividades productivas y económicas del país gracias a la mejora importante de la supraestructura de gestión e inversión pública, si bien la falta de una planificación turística y territorial adecuadas han provocado un desarrollo turístico espontáneo y desordenado y desde luego poco atento a los principios de la sostenibilidad, salvo casos excepcionales a nivel local o cantonal. En este sentido, Brown et. al. (2018) señalan la importancia de la zonificación territorial como mecanismo útil para adaptar la planificación territorial y la ordenación de los usos del suelo a las necesidades y casuísticas locales de desarrollo sostenible y crecimiento económico y urbanístico, lo que se tiene hoy día más que asumido en la mayor parte de las ciudades de los países desarrollados.

En Ecuador únicamente en el ámbito de las áreas protegidas del Estado se han aplicado planes de manejo desarrollados a partir de una zonificación de usos y ordenaciones de carácter territorial y específico, pero en cambio no han sido aplicados de manera sistemática en las ciudades y núcleos urbanos, pese a su necesidad imperiosa y la amplia experiencia existente a nivel mundial en planes generales ordenación urbana que puedan servir de referencia (Aranibar, 2013). No ha sido hasta muy recientemente, en el año 2011, cuando se ha aprobado el Código Orgánico de Ordenamiento Territorial y Descentralización (COOTAD), que ha supuesto un avance importante en la hasta ahora escuálida planificación y ordenamiento territorial de Ecuador. Esto es así en cuanto a que ha exigido esta norma a todos los Gobiernos Autónomos Descentralizados municipales y provinciales (GADS / GAPS) que implementen planes de ordenamiento territorial con la finalidad de optimizar el manejo y la planificación del territorio en función de sus potencialidades económicas, ambientales y turísticas, entre otras. Pero lo cierto es que pesar de sus esfuerzos, los objetivos aún no se han logrado debido a factores como la falta de criterios técnicos para el reordenamiento del territorio y los escasos presupuestos asignados, siendo el turismo uno de los sectores más afectados, en este sentido, ya que la actividad turística es una de las que más necesita de un desarrollo sostenible y equilibrado, capaz de generar beneficios indirectos a otras muchas actividades económicas relacionadas con el mismo por su carácter transversal característico.

Vista desde esta perspectiva, la zonificación busca evitar que los nuevos desarrollos interfieran negativamente con los existentes, así como preservar el "carácter" de la comunidad y los valores identitarios de su territorio además de implementar planes y políticas gubernamentales relacionadas con el desarrollo económico sostenible y la renovación urbana. La zonificación se ha ampliado desde entonces para incluir una gama más amplia de problemas y factores incidentes que incluyen las externalidades ambientales asociadas con el desarrollo urbano (contaminación, pérdida de tierras de cultivo), las raciales y socioeconómicas y las ligadas con la segregación y reducción general de la calidad de vida.

La zonificación aplicada a la planificación urbana y territorial es, en fin, el resultado tanto de un proceso sociopolítico (determinación de futuros objetivos de la comunidad relacionados con el uso del suelo) como de carácter técnico (es decir, el estudio concienzudo de las características físicas de la tierra para determinar cuáles son sus usos potenciales más sostenibles y adecuados). Como señala Steele (1986), la zonificación supone la puesta en marcha de un proceso legal que acaba por desencadenar procesos sociopolíticos de importante alcance, pero 
también puede representar, como de hecho ocurre, algunos conflictos entre usuarios del suelo en determinados espacios, lo que debe de identificarse mediante un mapeo participativo que describa la situación y que pueda dirimir dichos conflictos mediante el consenso entre actores implicados y un sistema de compensaciones que favorezcan a los más perjudicados, aunque siempre desde la perspectiva de la defensa en primer término de los intereses generales de la comunidad local (Brown \& Raymond, 2014).

La zonificación consta de dos componentes fundamentales: la delimitación de un área espacial que defina la zona y las regulaciones que se aplican a los usos del suelo dentro de la misma. Además de la cartografía general o específica de usos del suelo, adquiere una importancia central la redacción y revisión de las ordenanzas de usos del suelo para la zonificación, teniendo en cuenta diversas categorías (por ejemplo, residencial, comercial, industrial, turística...) que pueden o no estar conexionadas o relacionadas entre sí. La combinación de los mapas de zonificación y las ordenanzas proporcionan finalmente los usos legales del suelo y, en definitiva, las regulaciones necesarias para llevar a cabo las políticas del plan general identificadas por la autoridad del gobierno local. Para Torres et al (2013) la zonificación es una alternativa que permite direccionar gestiones de forma precisa y por áreas teniendo presente las características de cada una de ellas, pero una de las problemáticas más comunes a nivel de país es el desconocimiento de instrumentos y estrategias de gestión y planificación como lo es la zonificación, ya que no existe, por ejemplo en Ecuador, tradición planificadora al respecto y menos aún en el ámbito sectorial y económico como ocurre con la actividad turística.

Uno de los aspectos más importantes de la zonificación de espacios urbanos es la generación de políticas y normativas basadas en las mejoras de gestión ambiental (manejo de residuos, contaminación visual y acústica, etc.), ya que una de sus finalidades es la minimización de posibles impactos ambientales que se pudieran originar por parte de la actividad turística. Además, la zonificación turística pretende aportar también algunos criterios de sostenibilidad en aquellas zonas que presentan mayor fragilidad y, de esta manera, poder determinar qué áreas de la ciudad son aptas para el desarrollo del turismo y qué actividades alternativas se pueden desarrollar en otras. Por tanto, esta zonificación pretende cumplir con los Objetivos de Desarrollo Sostenible (ODS) y particularmente con el número 11 de las "Ciudades y comunidades sostenibles", que apunta a la necesidad de generar áreas públicas verdes y mejorar la planificación y gestión urbana de manera participativa e inclusiva (PNUD, 2018; Rivera, 2020).

Para Villegas (2015) la zonificación bien entendida pretende ser la base para determinar cómo se deben utilizar de la mejor manera posible los espacios territoriales, teniendo en cuenta criterios de equidad, cohesión territorial y equilibrio ambiental. Y esta zonificación se busca organizar de forma adecuada el territorio para determinar políticas públicas y normas de uso adecuadas, incluyendo la demarcación de límites, las condiciones de uso y sus restricciones, así como las acciones orientadas al uso racional de los recursos contando con la participación y opinión de la ciudadanía y los agentes locales (Doumet y Mendoza, 2015).

Desde otra perspectiva, la zonificación territorial urbana puede aportar nuevas orientaciones para la reconstrucción y planificación sostenibles de destinos turísticos de ciudad afectados por catástrofes socio-naturales, a partir del análisis de nuevas oportunidades y la reconducción mediante lecciones aprendidas de aquellas actuaciones anteriores puestas en cuestión por la dinámica de la catástrofe. De acuerdo con el Programa de las Naciones Unidas para el Desarrollo (PNUD, 2014) las últimas décadas han estado marcadas por un aumento exponencial de los costes derivados de la recuperación de muchos destinos como consecuencia de catástrofes de todo tipo y esto ha sido así particularmente en América Latina, donde entre 2005 y 2012 se han producido más de 240.000 fallecimientos, unos 57 millones de afectados y más de 
85 mil millones de dólares americanos en pérdidas. Pues bien, hoy día son muchos los autores que opinan que la gestión turística es un instrumento de interés para conocer y saber manejar de manera adecuada los recursos naturales y culturales de un determinado territorio, ya que suelen considerarse en la planificación sectorial turística otras políticas sectoriales y territoriales que inciden en la actividad turística o que, a la inversa, se ven afectadas por ésta última, como consecuencia de su transversalidad, de tal manera que se convierte en un ejemplo de respuesta integral para el correcto funcionamiento de cada uno de los componentes y piezas relevantes de cualquier sistema territorial (Obando et al, 2014).

El estudio de caso que aquí realizamos se localiza precisamente en uno de los destinos con mayor número de visitantes de Ecuador, el de la provincia de Manabí, con una oferta principal de sol y playa que se combina con una oferta más incipiente pero en continuo crecimiento en el segmento de turismo rural y gastronómico. Esta zona fue duramente golpeada en el año 2016 por un terremoto de 7.8 grados en la escala de Ritcher y, en concreto, fue la ciudad de Portoviejo, capital geopolítica de la provincia, uno de los epicentros de la catástrofe y por tanto de los más afectados, particularmente en su zona centro, donde se destruyeron centros comerciales, tiendas, museos, escuelas, edificios de dominio público, museos y monumentos y equipamientos turísticos, provocando incluso casi 200 fallecidos, según datos de la Secretaría Nacional de Riesgos (2016). Como consecuencia de la catástrofe se ha tenido que acometer de manera urgente la reconstrucción y reordenación urbana del área comercial, así como la recuperación de la economía del cantón en general, muy dependiente, por cierto, de una parte importante de los establecimientos, empresas y bienes patrimoniales que se ubicaban en dicho centro comercial de Portoviejo.

Al ser Portoviejo la capital geopolítica de la provincia de Manabí, ésta alberga las sedes provinciales de los principales ministerios del Estado como el Ministerio de Turismo, del Ambiente, de Relaciones Laborales y del Interior, entre otros. El Gobierno Provincial, el GAD municipal de Portoviejo y el Ministerio de Turismo son las instituciones que conforman la supraestructura turística local. En el año 2015 el GAD del cantón Portoviejo puso en ejecución el Plan de Ordenamiento Territorial y Desarrollo Cantonal, lo que permitió sentar las bases para un desarrollo y manejo eficiente del territorio, pero a pesar del potencial turístico de la ciudad y su entorno territorial, el plan indicado prácticamente no incluye previsiones y propuestas turísticas sustantivas y concretas.

De acuerdo con Félix (2016) cualquier tipo de planificación desarrollada anteriormente al terremoto, deja de tener la funcionalidad esperada, porque es necesario replantear todo y volver a los inicios, conocer la situación post-desastre no sólo en cifras sino también de manera cualitativa para poder atender las necesidades de los prestadores de servicios turísticos, que perdieron gran parte de sus negocios, y de las comunidades que quedaron aisladas y sin fuentes de recursos económicos, además de los atractivos inaccesibles y los servicios básicos colapsados. Pese a los intentos tanto del gobierno provincial como cantonal para reactivar la economía y el dinamismo de la ciudad, lo cierto es que éste no ha contado finalmente con una planificación y zonificación turística específica, lo que ha limitado sobremanera la obtención de resultados en materia de recuperación de la planta, los equipamientos y las infraestructuras turísticas afectadas. En el plan de ordenamiento territorial del cantón, ciertamente muy genérico, la ciudad de Portoviejo no aparece reconocida como un espacio de oportunidad turística, limitándose meramente a algunas actuaciones puntuales de regeneración urbana de algunos espacios, así como la implementación y mejoramiento de áreas verdes. 


\section{Metodología}

En este trabajo hemos tomado como referencia algunas investigaciones y estudios de caso (Becerra y Toledo, 2011; Aranibar, 2013; Pazmiño, 2015 y Quiguango, 2015), que han utilizado mecanismos de zonificación y planificación turística a la hora de ordenar y fomentar el desarrollo local con criterios de sostenibilidad. A partir de aquí la investigación ha tratado de diseñar una zonificación funcional turística para la ciudad de Portoviejo, incluyendo no solamente su casco urbano propiamente dicho si no también la parroquia de Picoazá, ya que ésta se encuentra dentro de la zona de influencia turística de la ciudad por la presencia del complejo arqueológico "Cerro de Hojas y Jaboncillo".

El método de trabajo de la investigación ha sido fundamentalmente de carácter exploratorio descriptivo, si bien se han utilizado técnicas y herramientas complementarias tanto de carácter cualitativo como cuantitativo. A continuación, en el siguiente Cuadro 1, se presenta el proceso metodológico seguido en este trabajo.

Cuadro 1. Procedimiento Metodológico del estudio

\begin{tabular}{|c|c|c|c|}
\hline Fases & Actividades & Métodos & Técnicas /herramientas \\
\hline \multirow{2}{*}{$\begin{array}{l}\quad \text { I. } \\
\text { Diagnóstico } \\
\text { turístico del área } \\
\text { de estudio }\end{array}$} & $\begin{array}{l}\text { - } \quad \text { Revisión de la } \\
\text { bibliografía y } \\
\text { documentos oficiales }\end{array}$ & $\begin{array}{l}\text { Análisis } \\
\text { bibliográfico de } \\
\text { revisión }\end{array}$ & $\begin{array}{lll}\text { - } & \text { Bibliográfica } & \\
\text { - } & \text { Plan } \\
\text { ordenamiento } & \\
\text { territorial. } & \\
\text { - } & \begin{array}{l}\text { Informes } \\
\text { terremoto }\end{array}\end{array}$ \\
\hline & $\begin{array}{l}\text { - Análisis FODA del } \\
\text { sistema turístico de } \\
\text { la ciudad de } \\
\text { Portoviejo }\end{array}$ & $\begin{array}{l}\text { Análisis } \\
\text { deductivo }\end{array}$ & $\begin{array}{ll}\text { - } & \text { Matriz FODA } \\
\text { - } & \text { Matriz de } \\
\text { involucrados/Focus } \\
\text { Group }\end{array}$ \\
\hline $\begin{array}{l}\quad \text { II. } \\
\text { Distribución } \\
\text { geoespacial y } \\
\text { lineamientos } \\
\text { para la } \\
\text { zonificación } \\
\text { turística }\end{array}$ & 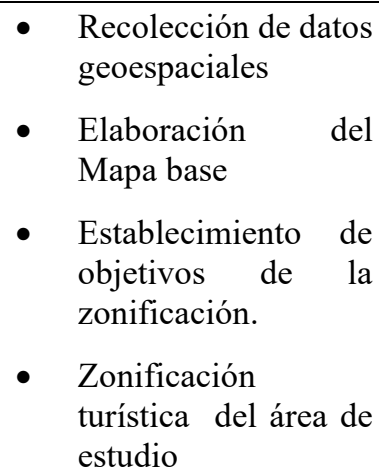 & $\begin{array}{l}\text { Cartografía } \\
\text { temática } \\
\text { georreferenciada }\end{array}$ & $\begin{array}{l}\text { - GPS, Fichas de } \\
\text { registro } \\
\text { - } \begin{array}{l}\text { Observación } \\
\text { visitas de campo y }\end{array} \\
\text { - Google Earth } \\
\text { (cartografía digital). } \\
\text { - Google Maps } \\
\text { Engine }\end{array}$ \\
\hline
\end{tabular}

Fuente: Elaboración propia

Portoviejo es una de las ciudades más antiguas de la costa ecuatoriana, de manera que aún conserva ciertos recursos de interés patrimonial y, asimismo, cuenta con una geografía accidentada, con pequeñas elevaciones entre los 200 y 250 metros sobre el nivel del mar, rodeadas de bosques de ceibos y guayacanes, lo que configura un paisaje ciertamente singular 
en el entorno de a ciudad. Su clima es, por otra parte, muy versátil, pues en verano el clima es templado, mientras que en invierno es muy caluroso. La temperatura promedio es de 24 grados centígrados y las precipitaciones anuales son muy escasas al comprenderse entre los 500 y los $100 \mathrm{~mm}^{3}$.

La ciudad de Portoviejo es la capital geopolítica de la provincia de Manabí (Figura 1) y donde se concentra gran parte de la población económicamente activa de la región debido a su ubicación geográfica y la importante presencia del sector público y comercial. Teniendo en cuenta que una gran parte de la afectación sísmica de la ciudad tras el terremoto de 2016 se localizó en su infraestructura y planta turística, en este trabajo se ha optado por dar prioridad a la identificación de los espacios turísticos reales y potenciales antes y después del terremoto como paso previo a la realización de una prospectiva de desarrollo turístico y comercial en los mismos como contribución al desarrollo integral de esta ciudad y su recuperación urbana en todos los sentidos.

Figura 1. Mapa de la zona urbana y rural de Portoviejo

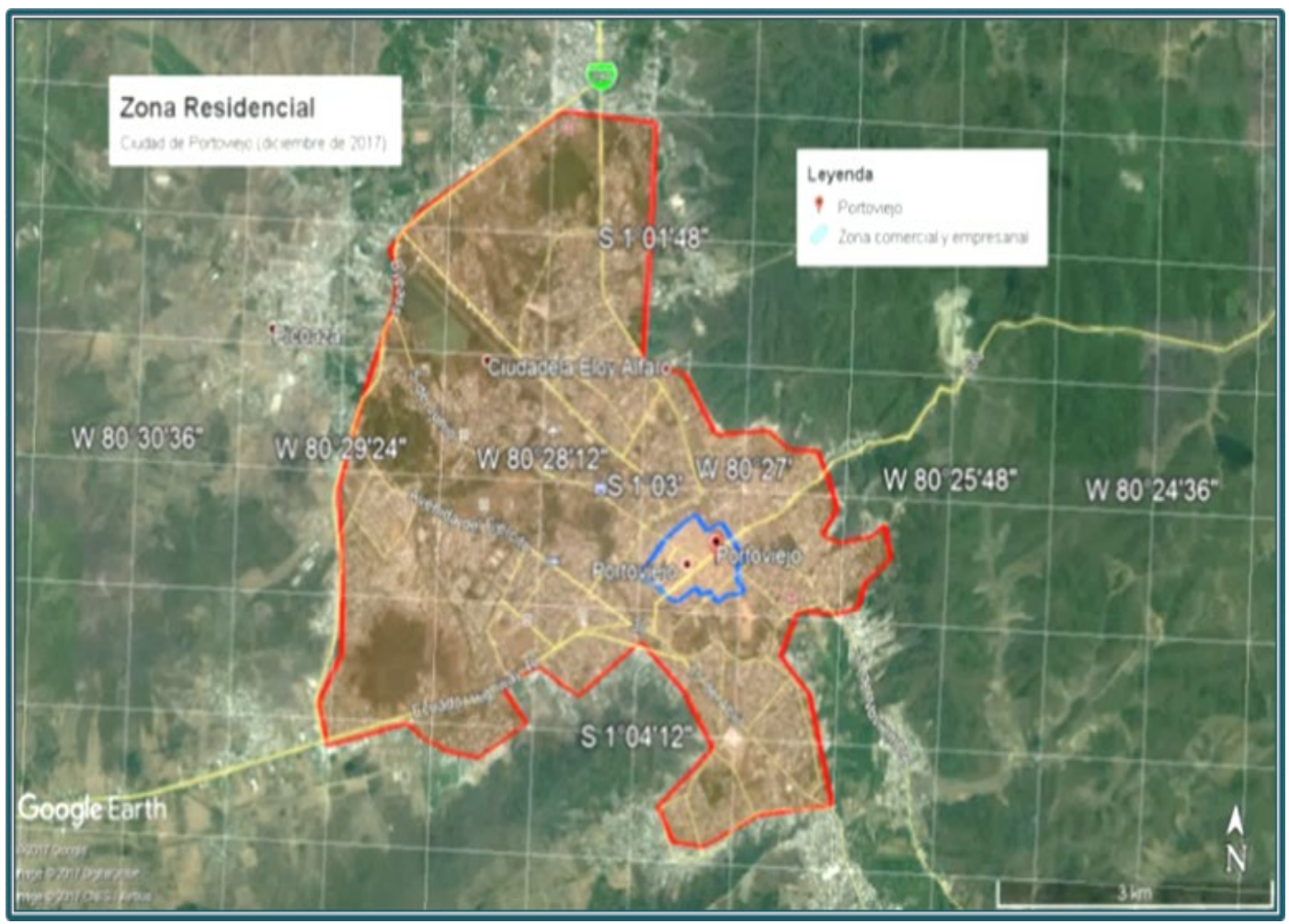

Fuente. Elaboración propia a partir de cartografía de base de Google Maps.

Como parte fundamental del método de estudio, se ha realizado un importante trabajo de campo para la determinación del estado actual de las infraestructuras, las condiciones de movilidad, los servicios básicos, los aspectos sociales, económicos, ambientales y políticos y el marco institucional, tras lo cual se ha procedido a evaluar y diagnosticar los factores visibles 
que limitan o promueven el desarrollo integral de la ciudad, todo esto mediante la caracterización previa del mapa de actores de la zona de estudio y la consulta a los agentes locales y stakeholders involucrados en la misma. Para esto fue necesario valorar las condiciones de las dimensiones anteriormente mencionada y analizar dichos datos mediante una matriz FODA.

\section{Resultados y discusión.}

Los resultados más importantes y significativos derivados del análisis FODA y de las consultas realizadas a los agentes locales de la ciudad y cantón de Portoviejo han sido recogidos y estructurados en el Cuadro 2 siguiente:

\section{Cuadro 2. Matriz FODA del sistema turístico de la ciudad de Portoviejo}

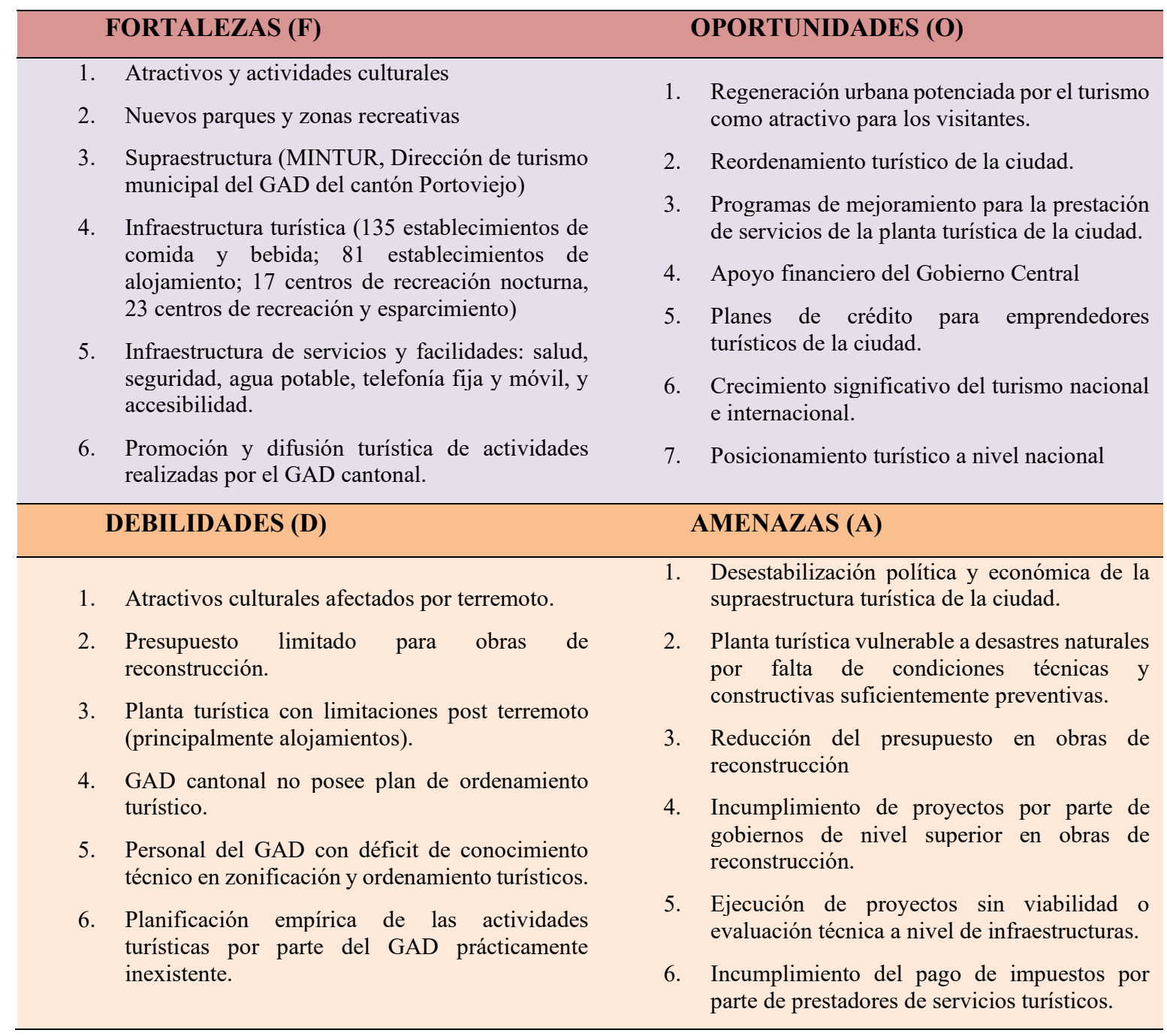

\section{Fuente. Elaboración propia}

Una vez desarrollado dicho análisis estableciendo puntos claves para la matriz de evaluación, se llevó a cabo una valoración para permitir identificar de forma objetiva cuáles son las principales oportunidades y fortalezas del sistema turístico de Portoviejo frente a sus 
debilidades y amenazas detectadas. Para esto fue necesario aplicar una ponderación básica de relación entre las variables identificadas (Poco, Regular, Mucho), que se representa en el Cuadro 3 siguiente.

\section{Cuadro 3. Matriz FODA de variables identificadas en el análisis externo}

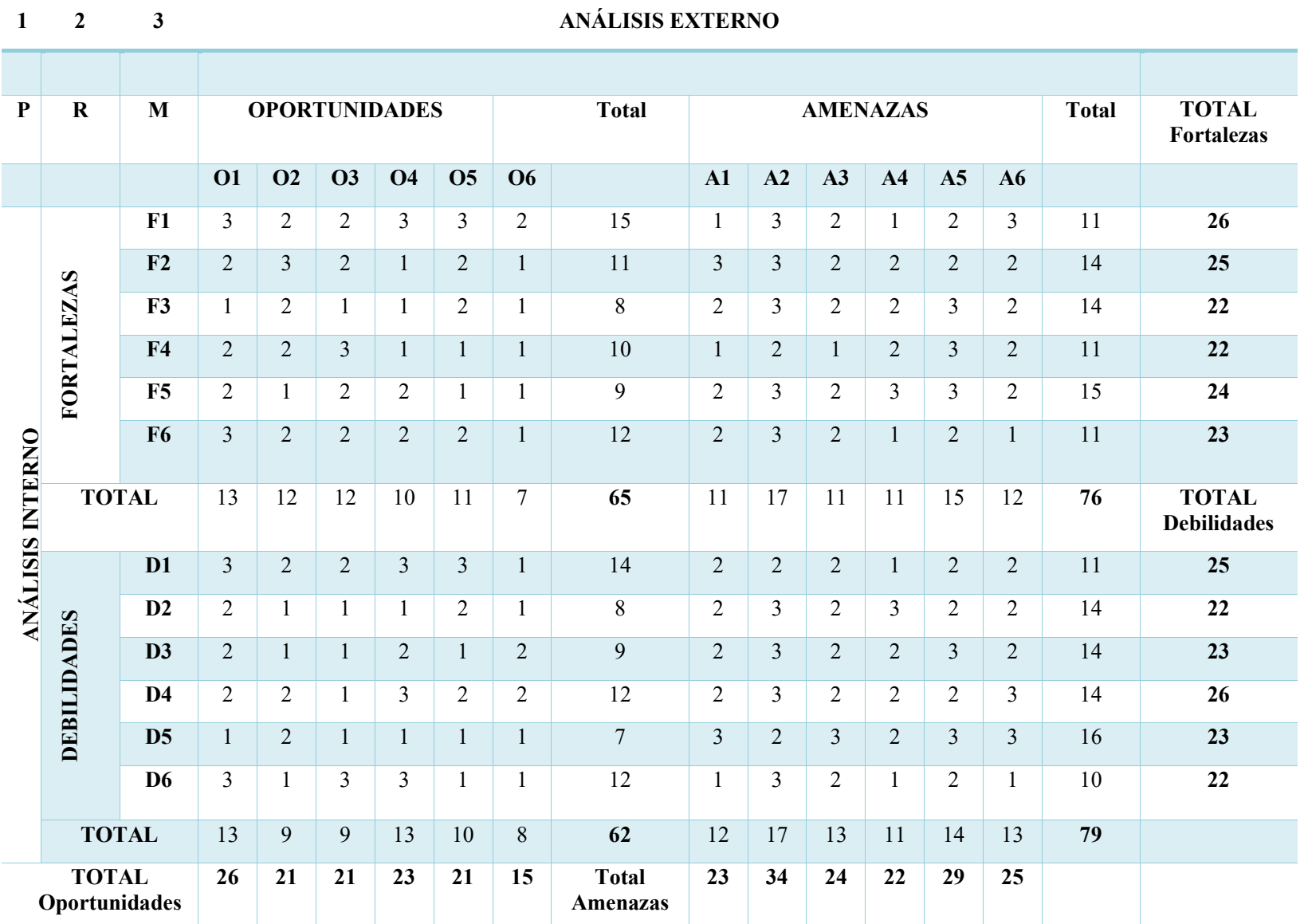

Fuente. Elaboración propia

Según los resultados expuestos en el Cuadro 3, los ejes O1 y D2, son los que mayor ponderación alcanzan, lo que supone que la regeneración urbana de Portoviejo se constituye en una de las principales oportunidades para el desarrollo del cantón, si bien una de las mayores debilidades detectadas es el limitado presupuesto municipal para las obras de reconstrucción tras la catástrofe natural. Por otra parte, el sistema turístico de la ciudad de Portoviejo permanece activo y las instituciones, tanto públicas como privadas, se encuentran funcionando con normalidad en la actualidad y a pesar de que con el terremoto una parte de la planta hotelera y de restauración quedó afectada, estas lograron finalmente reactivarse en su mayoría. Los atractivos culturales de la ciudad, por su parte, quedaron muy afectados, pero en la actualidad se encuentran en proceso de reconstrucción y restauración y además se han activado nuevas áreas para la recreación y el esparcimiento público. Por otro lado, la ciudad posee otros recursos que pretenden ser incluidos a la oferta turística urbana, como es el caso del parque "La Rotonda" y el nuevo y restaurado parque temático "Las Vegas", intentando con ello potenciar e innovar el turismo de la capital y redefinir las zonas turísticas de Portoviejo. 
En este proceso de reconstrucción del destino turístico las instituciones públicas y privadas ligadas al manejo y regulación de la actividad turística han de aunar esfuerzos para que todos los proyectos que se prevean se desarrollen siguiendo criterios e indicadores de sostenibilidad. Actualmente, al menos, la ciudad de Portoviejo -que durante muchos años estuvo prácticamente ensombrecida por la modernidad y pujanza de otras ciudades de la provincia como Manta- ha conseguido alcanzar una visión y marca identitaria e innovadora, superando las secuelas de la catástrofe del 16 de abril de 2016 a través de la buena gestión relativa del GAD cantonal. Pero para alcanzar objetivos de más largo alcance ha de existir un sistema de gobernanza, un modelo de organización bien diseñado metodológicamente y una planificación sectorial sustentada en la colaboración público-privada, una base normativa sólida y un presupuesto suficiente, además de una zonificación territorial de regulación y control de usos del suelo (Rivera y Félix, 2018; Rivera y Félix, 2019). De estas premisas, la ciudad de Portoviejo ya cuenta desde 2015 con un Plan de Ordenamiento Territorial con unas categorías de ordenación específicas en unidades ambientales que afectan al entorno de valles agrícolas del río Portoviejo, a su paso por la localidad, y las áreas agrícolas de cultivos de ciclo corto, zonas agroforestales del bosque seco existente y algunas áreas para el desarrollo de actividades de ecoturismo.

Asimismo, dado que el área urbana de la ciudad posee un perímetro aproximado de 26,4 kilómetros y ocupa una superficie de 22,5 kilómetros cuadrados a la redonda (Google Earth, 2017), se han podido determinar en el POT las siguientes áreas para el desarrollo social y turístico (Figura 2): Zona de uso sostenible, Zona turística, Zona residencial, Zona comercial y empresarial y Zonificación Funcional Turística de la ciudad de Portoviejo.

Figura 2. Distribución geoespacial del área de estudio

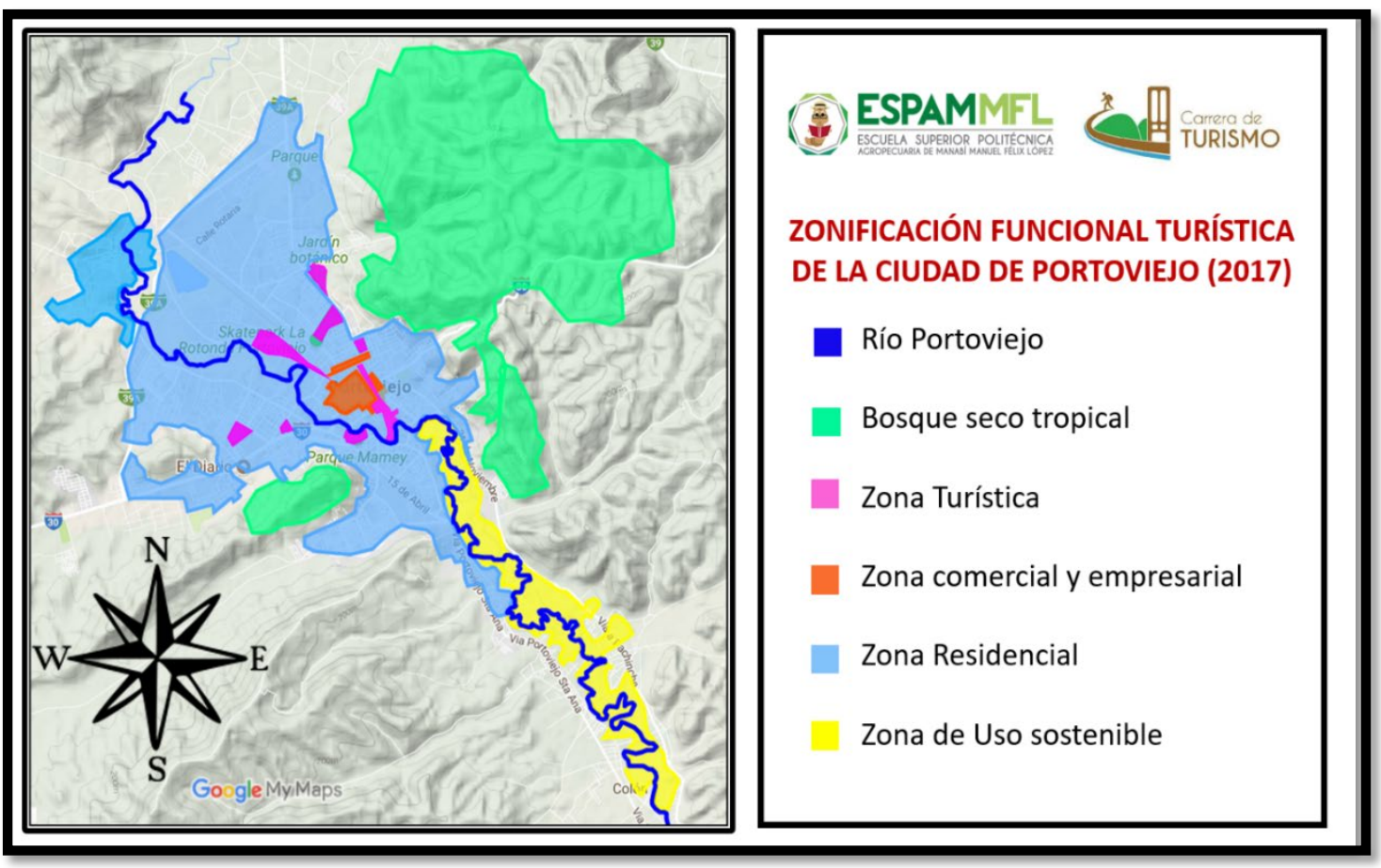

Fuente. Elaboración propia a partir de base cartográfica de Google Maps. 
La zona de uso sostenible delimitada en el POT comprende las áreas dedicadas a los cultivos que se encuentran alrededor del área suburbana de la ciudad de Portoviejo. La importancia de esta zona radica en el buen uso del suelo y las necesidades de regeneración de la capa edáfica y arbustiva. En esta área no existen atractivos turísticos culturales y naturales registrados como tales, pero el potencial que posee para el desarrollo de actividades agroturísticas es importante, lo que permitiría diversificar y ampliar la oferta turística de la ciudad en su entorno más cercano. Esta zona (Figura 3) abarca una extensión de cinco kilómetros cuadrados, entre las coordenadas $1^{\circ} 05^{\prime} 36.59^{\prime \prime}$ de longitud Sur y $80^{\circ} 25^{\prime} 12.25^{\prime \prime}$ de latitud Oeste y su paisaje está dominado principalmente por cultivos de ciclo corto, así como también de diversas variedades de cultivos como palmas de coco, cacao, limón, naranja, entre otros, y en menor escala por la crianza de ganado vacuno y porcino.

Figura 3. Zona de uso sostenible de la ciudad de Portoviejo

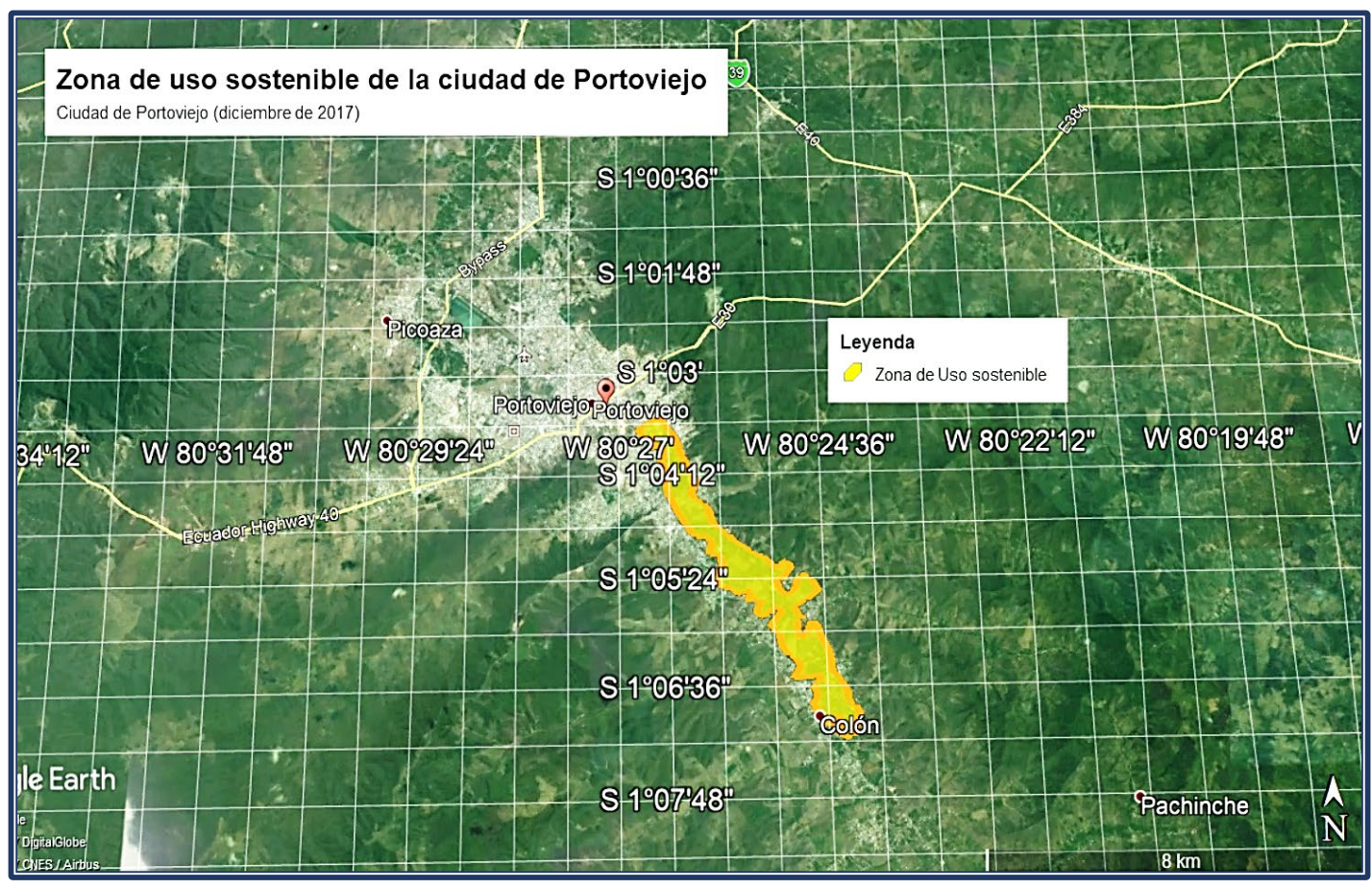

Fuente: Elaboración propia a partir de cartografía de base de Google Earth.

El objetivo funcional de esta área no es otro que el de promover el uso racional y sostenible de los recursos agropecuarios y culturales en la zona suburbana de la ciudad de Portoviejo, de manera que se establecen las siguientes directrices de gestión y manejo:

a) El GAD municipal del cantón de Portoviejo asignará y coadyuvará al uso sustentable de los recursos naturales de la zona de uso sostenible a tasas que garanticen su capacidad de renovación, con el fin de atenuar los impactos y asegurar la sustentabilidad de los ecosistemas en el interior del área.

b) La dirección provincial del Ministerio del Ambiente incrementará la participación efectiva de las comunidades y poblaciones locales del interior en el manejo y desarrollo de funciones de protección de sus ecosistemas. 
c) Se permitirá que las comunidades realicen actividades compatibles con el mantenimiento de la diversidad biológica, del patrimonio cultural, de los procesos ecológicos, y la oferta de usos tradicionales, particularmente los usos recreativos ligados a los recursos del área.

d) El Gobierno provincial y el GAD municipal de Portoviejo garantizarán el acceso a los servicios básicos, así como la recolección y disposición de desechos orgánicos e inorgánicos.

e) El Ministerio del Interior deberá implementar sistemas de vigilancia y de circuito integrado al sistema ECU911, así como de UPC para garantizar la seguridad y bienestar de los habitantes.

f) Los habitantes del área deberán fomentar las buenas prácticas del uso responsable de los recursos naturales y energéticos para mitigar los impactos al medio biótico y abiótico.

La zona turística de la ciudad de Portoviejo (Figura 4.) se encuentra distribuida en varios sectores donde se concentra la mayor afluencia de visitantes debido al buen estado de sus equipamientos e infraestructuras y la existencia de algunos atractivos monumentales y patrimoniales.

Figura 4. Zona turística de la ciudad de Portoviejo

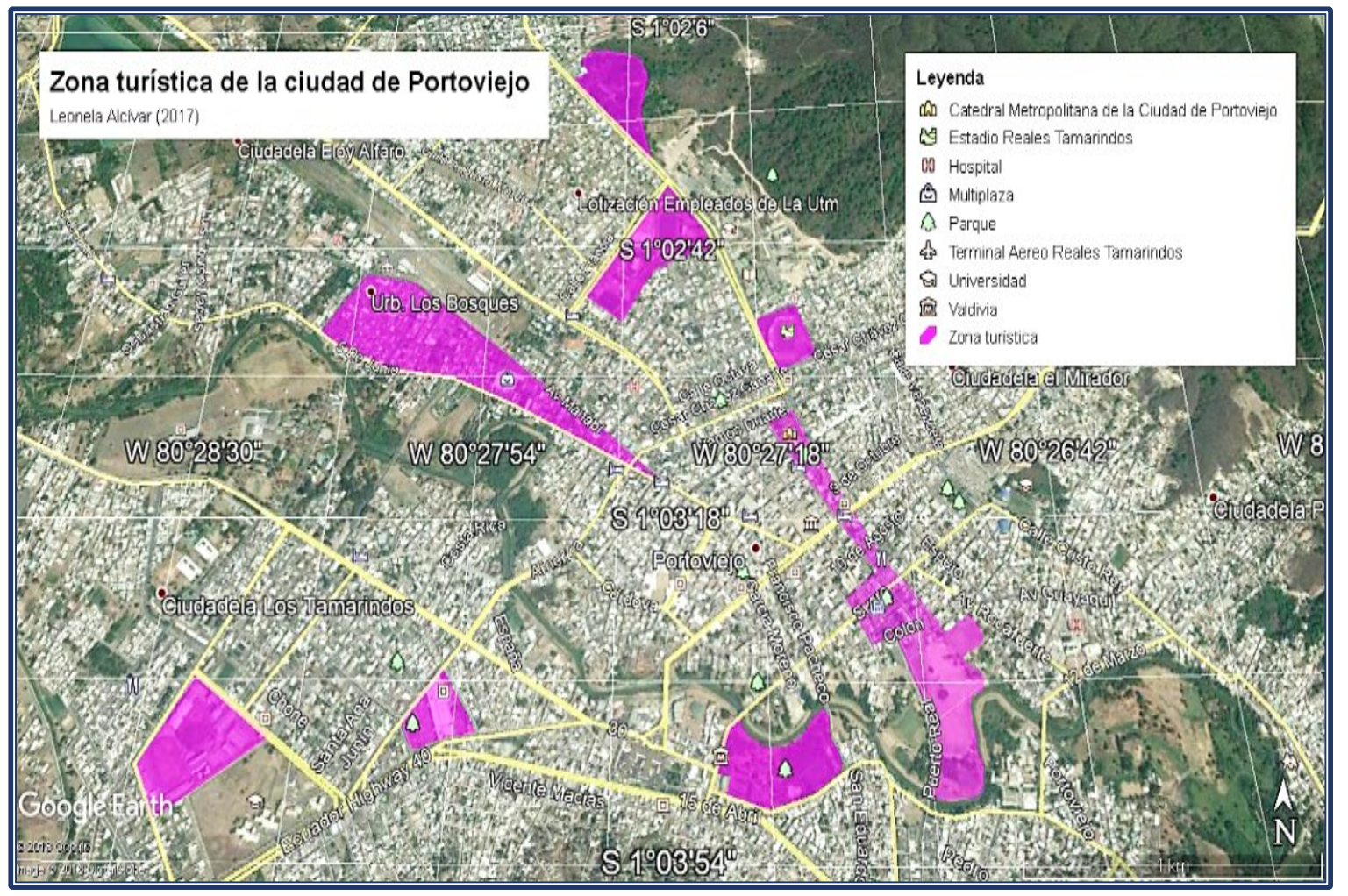

Fuente: Elaboración propia a partir de base cartográfica de Google Earth.

Por su parte, dentro de la zona de influencia comercial y de servicios se encuentran diversos recursos considerados dentro del sector turístico o como parte de la oferta de recreación que debido a las consecuencias del terremoto del 16A se vieron fuertemente afectadas y luego 
mejoradas a nivel de infraestructura y servicios básicos por la gestión de las autoridades del Gobierno Autónomo Descentralizado del Cantón Portoviejo. A continuación, en el Cuadro 4, se presentan las manifestaciones culturales y lo espacios turísticos considerados en este estudio:

Cuadro 4. Manifestaciones culturales y espacios turísticos de la ciudad de Portoviejo

\begin{tabular}{|c|c|c|c|}
\hline \multicolumn{4}{|c|}{ Manifestaciones Culturales y espacios turísticos de la ciudad de Portoviejo } \\
\hline Espacios y atractivos de interés turístico & Dirección & Georref & \\
\hline Parque Las Vegas & Ricaurte y Colón & $\begin{array}{l}1^{\circ} 03 ’ 35.19^{\prime \prime} \\
80^{\circ} 26^{\prime} 57.84 ” \mathrm{O}\end{array}$ & $\mathrm{S}$ \\
\hline Parque ecológico el Mamey & Miguel Alcívar y Teodoro Wolf & $\begin{array}{l}1^{\circ} 03 ’ 42.21^{\prime \prime} \\
80^{\circ} 27^{\prime} 23.00^{\prime \prime} \mathrm{O}\end{array}$ & $\bar{S}$ \\
\hline $\begin{array}{l}\text { Parque Vicente Amador Flor y centro } \\
\text { histórico de la ciudad }\end{array}$ & Olmedo y Sucre & $\begin{array}{l}1^{\circ} 03 ' 27.43^{\prime \prime} \\
80^{\circ} 27^{\prime} 03.61^{\prime \prime} \mathrm{O}\end{array}$ & $\mathrm{S}$ \\
\hline Parque Eloy Alfaro & $\begin{array}{l}\text { Francisco de P. Moreira y Av. } \\
\text { Universitaria }\end{array}$ & $\begin{array}{l}1^{\circ} 03 ’ 10.35^{\prime \prime} \\
80^{\circ} 27^{\prime} 12.36 " \mathrm{O}\end{array}$ & $\mathrm{S}$ \\
\hline Parque de Las Madres & Av. América y Ricaurte & $\begin{array}{l}1^{\circ} 03 ’ 03.75^{\prime \prime} \\
80^{\circ} 27^{\prime} 22.50^{\prime \prime} \mathrm{O}\end{array}$ & $\mathrm{S}$ \\
\hline Parque La Rotonda & $\begin{array}{l}\text { Av. Pablo Zamora y Av. } \\
\text { Universitaria }\end{array}$ & $\begin{array}{l}1^{\circ} 02^{\prime} 37.08^{\prime \prime} \\
80^{\circ} 27^{\prime} 26.48^{\prime \prime} \mathrm{O}\end{array}$ & $\mathrm{S}$ \\
\hline Parque Andrés de Vera & $\begin{array}{l}\text { Av. América y Jorge } \\
\text { Washington }\end{array}$ & $\begin{array}{l}1^{\circ} 03 ’ 41.32^{\prime \prime} \\
80^{\circ} 27^{\prime} 57.88^{\prime \prime} \mathrm{O}\end{array}$ & $\mathrm{S}$ \\
\hline Iglesia La Merced & Ricaurte y Simón Bolívar & $\begin{array}{l}1^{\circ} 03 ’ 30.74^{\prime \prime} \\
80^{\circ} 27^{\prime} 04.34 ” O\end{array}$ & $\mathrm{~S}$ \\
\hline Iglesia El Sagrario & Sucre y Ricaurte & $\begin{array}{l}1^{\circ} 03 ’ 26.66^{\prime \prime} \\
80^{\circ} 27^{\prime} 05.34 ”\end{array}$ & $\mathrm{~S}$ \\
\hline Iglesia Pio Noveno & América y Córdoba & $\begin{array}{l}1^{\circ} 03 ’ 24.08^{\prime \prime} \\
80^{\circ} 27^{\prime} 39.90^{\prime \prime} \mathrm{O}\end{array}$ & $\mathrm{S}$ \\
\hline Iglesia Catedral "Jesús el buen pastor" & $\begin{array}{l}\text { Francisco de P. Moreira y Av. } \\
\text { Universitaria }\end{array}$ & $\begin{array}{l}1^{\circ} 03^{\prime} 08.94^{\prime \prime} \\
80^{\circ} 27^{\prime} 13.31^{\prime \prime} \mathrm{O}\end{array}$ & $\mathrm{S}$ \\
\hline Museo Portoviejo & Sucre y Olmedo & $\begin{array}{l}1^{\circ} 03 ’ 25.42^{\prime \prime} \\
80^{\circ} 27^{\prime} 03.52^{\prime \prime} \mathrm{O}\end{array}$ & $\mathrm{S}$ \\
\hline Estadio deportivo "Reales Tamarindos". & $\begin{array}{l}\text { Av. Universitaria y César } \\
\text { Chávez Cañarte }\end{array}$ & $\begin{array}{l}1^{\circ} 02^{\prime} 55.03 " \\
80^{\circ} 27^{\prime} 16.64 ”\end{array}$ & $\mathrm{~S}$ \\
\hline Centro Comercial Paseo Shopping & $\begin{array}{l}\text { Av. América y Jorge } \\
\text { Washington }\end{array}$ & $\begin{array}{l}1^{\circ} 03^{\prime} 40.099^{\prime \prime} \\
80^{\circ} 27^{\prime} 56.47^{\prime \prime} \mathrm{O}\end{array}$ & $\mathrm{S}$ \\
\hline Centro Comercial Multiplaza & Av. 5 de Junio & $\begin{array}{l}1^{\circ} 03 ’ 02.39^{\prime \prime} \\
80^{\circ} 27^{\prime} 51.52^{\prime \prime} \mathrm{O}\end{array}$ & $\mathrm{S}$ \\
\hline Complejo deportivo La California & Av. Olímpica y Av. Bolivariana & $\begin{array}{l}1^{\circ} 03 ’ 38.35^{\prime \prime} \\
80^{\circ} 28^{\prime} 20.50^{\prime \prime} \mathrm{O}\end{array}$ & $\mathrm{S}$ \\
\hline $\begin{array}{c}\text { Jardín Botánico de la Universidad Técnica de } \\
\text { Manabí }\end{array}$ & $\begin{array}{l}\text { Av. Universitaria y calle } \\
\text { Álamos }\end{array}$ & $\begin{array}{l}1^{\circ} 02^{\prime} 18.75^{\prime \prime} \\
80^{\circ} 27^{\prime} 40.47^{\prime \prime} \mathrm{O}\end{array}$ & $\mathrm{S}$ \\
\hline Total Atractivos & 17 & & \\
\hline
\end{tabular}

Fuente: Elaboración propia a través de trabajo de campo. 
Como se observa en la Figura 5, la zona turística de la ciudad de Portoviejo cuenta con atractivos culturales distribuidos por toda la urbe (Cuadro 5), sumando un total de 17, entre los que destacan los de carácter religioso (iglesias y capillas), así como también los de recreación y esparcimiento (centros comerciales, parques, bares y discotecas).

Figura 5. Espacios turísticos, recreativos y de esparcimiento de la ciudad de Portoviejo

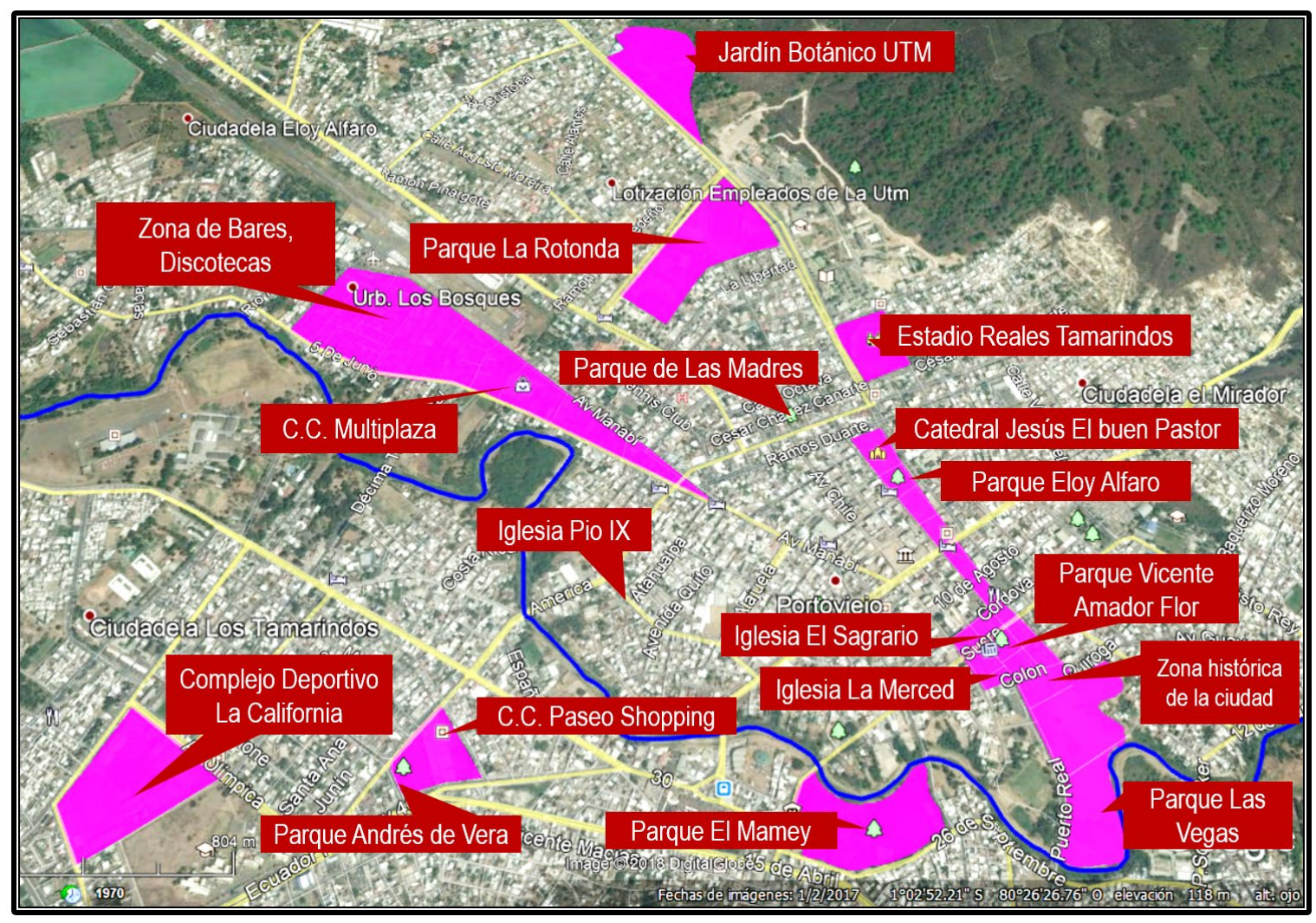

Fuente. Elaboración propia

El objetivo de esta zona turística delimitada como tal en la ciudad de Portoviejo es garantizar una serie de facilidades para el bienestar y seguridad de los visitantes, así como una serie de servicios turísticos de calidad y sistemas de soporte de los mismos debidamente adecuados para su sostenimiento. Para conseguir este fin general, la ciudad de Portoviejo, a través de sus entidades de coordinación de la actividad turística (Departamento de Turismo del GAD del cantón Portoviejo, Ministerio de Turismo, Instituto Nacional de Cultura y Patrimonio (Ministerio de Cultura), Ministerio del Interior), pretende implementar las siguientes políticas de manejo turístico:

a) Las áreas turísticas de la ciudad facilitarán a los visitantes el acceso a servicios que garanticen su bienestar durante su tiempo de permanencia en la ciudad, tales como servicios básicos, incluyendo infraestructura de accesibilidad.

b) Las áreas de mayor uso intensivo como Parques, que deberán garantizar la ubicación de infraestructura: servicios higiénicos, centros de información turística, ventas de souvenirs y puntos de restauración. 
c) La fuerza pública deberá ubicar UPC (Unidad de Policía Comunitaria) y rutas de patrullaje permanente en las áreas turísticas de la ciudad para garantizar el bienestar y la seguridad de los visitantes durante su estadía o permanencia en la urbe.

d) El GAD municipal de Portoviejo establecerá un sistema de impuestos económicos del $5 \%$ adicional por consumo de servicios y productos en áreas turísticas para garantizar el sostenimiento y mantenimiento de las mismas.

e) Todas las áreas turísticas deberán contar con sistemas de recogida diaria de residuos para evitar la acumulación inmediata de los mismos y la reproducción de agentes biológicos nocivos para el ser humano, así como de cualquier tipo de plaga.

f) Los desechos generados en las áreas de mayor afluencia turística deberán contar con planes de mitigación y disposición de los mismos.

g) El departamento de Turismo del GAD Portoviejo coordinará en intervalos semestrales o anuales la capacitación en aspectos de gestión de la calidad a los prestadores de servicios turísticos de la ciudad: operadores de turismo, agentes de transportes, establecimientos de alojamiento, restauración y artesanos. Dichas capacitaciones serán de carácter obligatorio, pero en caso de no participación se dispondrá de una sanción económica a los establecimientos, así como la suspensión temporal o inmediata de sus actividades.

h) El GAD municipal dotará de conectividad inalámbrica a redes de internet en las áreas mayor afluencia turística de la ciudad de forma abierta y gratuita. También se incluirán puntos de acceso a carga de energía para dispositivos móviles desde eco generadores.

i) La ciudad contará con sistemas de información móviles (apps móviles), sobre transporte, puntos de información turística, actividades y agenda turística de la ciudad, así como también la dotación de señalética turística y ambiental (infogramas, letreros, pictografía, mapas, vallas, etc.).

j) La ciudad de Portoviejo, a través de la coordinación de Cultura, y todas las instituciones y departamentos vinculados a esta área, dispondrán de una agenda mensual o bimestral de actividades culturales en espacios de la urbe que posean la capacidad necesaria para acoger a la población local participante.

k) Las áreas turísticas deberán estar integradas dentro de los sistemas de vigilancia del ECU911, con monitoreo permanente y conectividad, principalmente en los espacios dispuestos para el estacionamiento vehicular y sitios de afluencia masiva, así como también el auxilio inmediato en caso de accidentes que pongan en riesgo la integridad física de los visitantes.

1) Las zonas de mayor influencia deberán contar con pequeños centros de salud para la salvaguarda y auxilio en caso de incidentes que pongan en riesgo la integridad de los visitantes.

m) Implementar mecanismos de control y monitoreo para evitar la contaminación producida por automotores en mal estado, así como la degradación del paisaje urbano, entre otros tipos de agentes contaminantes como el ruido y exceso de luz artificial.

n) Promover la utilización de energías verdes en espacios turísticos a fin de optimizar los recursos energéticos de la ciudad.

La denominada zona residencial de la ciudad de Portoviejo comprende los espacios destinados para el establecimiento de viviendas y residencias de los habitantes de la urbe (Figura 6). La zona de mayor crecimiento urbanístico se encuentra situada hacia el noroccidente 
de la ciudad, ya que algunos de estos espacios se encuentran ocupados por complejos habitacionales públicos y privados. Esta área ocupa una extensión de 27 kilómetros cuadrados.

Figura 6. Zona Residencial de la ciudad de Portoviejo

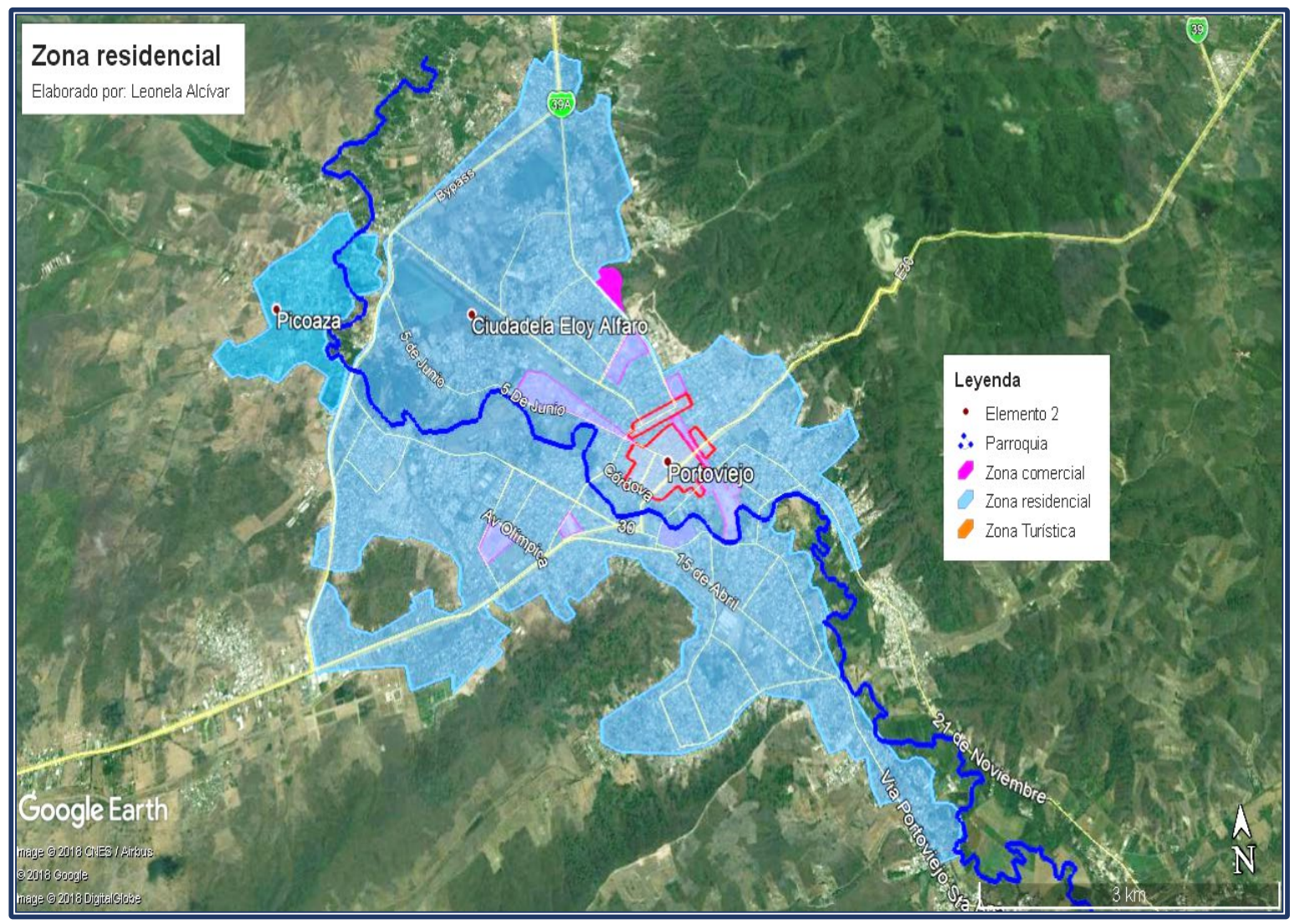

Fuente Elaboración Propia a partir de base cartográfica de Google Earth.

El objetivo de esta zona residencial es facilitar las herramientas necesarias para que los ciudadanos residentes en el perímetro urbano de la ciudad de Portoviejo gocen de un entorno saludable, tranquilo y seguro. Para ello se establecen en el POT las siguientes determinaciones, cuyo cumplimiento correrá a cargo de la coordinación del GAD cantonal, los Comités y las Asociaciones de Barrios de la ciudad:

a) Las autoridades competentes dotarán a los barrios con sistemas de vigilancia comunitaria, monitoreo y circuito integrado al sistema ECU911.

b) Los barrios y conjuntos residenciales privados contarán con sistemas y horarios de recolección de basura en intervalos de 48 horas laborables.

c) Los barrios deberán contar con infraestructura de acceso y dotación de servicios básicos, electricidad, alumbrado público, agua potable, telefonía fija y móvil, alcantarillado pluvial-sanitario, así como de acceso vial o peatonal en buen estado. 
d) La comunidad de barrio y zonas residenciales deberán acoger y brindar la información y ayuda necesaria a los turistas que visiten la ciudad de Portoviejo.

e) Los comités de barrio y asociaciones deben garantizar la pulcritud y buenas prácticas higiénicas para la disposición de los desechos orgánicos e inorgánicos a fin de evitar que se acumulen es espacios públicos que contribuyan a la proliferación de agentes nocivos para el ser humano, y sobre todo que agredan a la buena imagen de la ciudad.

f) Dotar de señalización vial, ambiental y turística a fin de que el acceso y tránsito de la ciudad sea entensible para cualquier visitante nacional o extranjero.

Por último, se ha definido la zona comercial y empresarial (Figura 7), en la que se encuentran las áreas de mayor concentración del comercio formal e informal de la ciudad de Portoviejo, así como también las principales entidades financieras (públicas y privadas), oficinas ministeriales, gobierno municipal y provincial, palacio de justicia y telecomunicaciones, entre otras instituciones del sector privado y público.

Figura 7. Zona Comercial y Empresarial

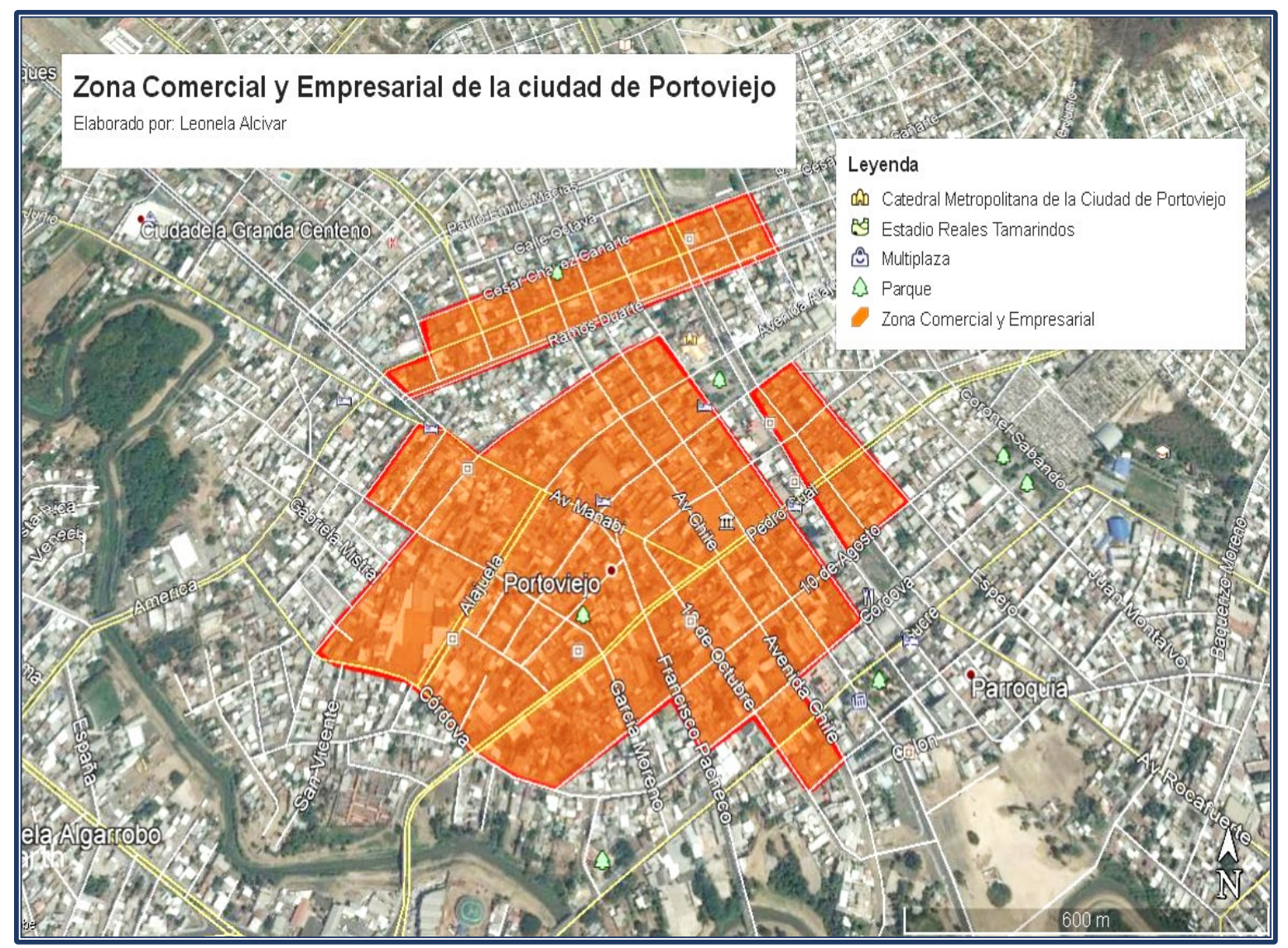

Fuente. Elaboración propia a partir de base cartográfica de Google Earth.

El objetivo de esta zona es dinamizar el comercio y la gestión empresarial a través de un servicio de calidad que promueva una cultura turística en la ciudad de Portoviejo, para lo cual se plantean las siguientes determinaciones: 
a) El buen proceder y prestación de servicios de calidad con calidez y objetividad a sus usuarios.

b) Garantizar la accesibilidad a los servicios que por competencia deban facilitar a la comunidad portovejense y del resto del país, o inclusive extranjeros.

c) La participación y colaboración activa con las actividades culturales y turísticas que coordinen las autoridades competentes de la ciudad.

d) El pago puntual de impuestos para el sostenimiento de la infraestructura básica y servicios de la ciudad.

e) Otorgar facilidades en cuanto a asesoría técnica y financiamiento de pequeños y grandes emprendimientos turísticos.

f) La buena presentación e imagen de los locales comerciales y de las entidades financieras y gubernamentales.

g) Facilitar el tránsito a los peatones en áreas de cogestión a causa del comercio informal.

h) Disposición de los residuos orgánicos e inorgánicos en los espacios y receptores de basura asequibles en el área de influencia.

i) Garantizar el consumo responsable de energía, así como el pago a tiempo de las planillas de servicio eléctrico, agua y telecomunicaciones.

j) Brindar información a los turistas durante su permanencia y estadía en la ciudad de Portoviejo.

\section{Conclusiones}

El sistema turístico de la ciudad de Portoviejo se encuentra actualmente activo, incluyendo también la planta hotelera, a pesar de las afectaciones importantes que sufrió tras el terremoto de 2016. No obstante, todavía hay establecimientos hoteleros y otros tipos de alojamientos en proceso de reconstrucción y mejora, que incluso están aprovechando la etapa postcrisis para introducir algunas innovaciones y adecuarse a las nuevas exigencias de la demanda, a lo que se están sumando nuevos proyectos relacionados con el comercio, el ocio y la recreación. La situación actual denota una recuperación importante del sector turístico, sobre todo si la comparamos con otras ciudades de la provincia de Manabí o provincias aledañas, lo que podemos asociar a un sistema de gestión y gobernanza post crisis más desarrollado que en otros núcleos de población afectados por el mismo desastre natural.

Un factor importante de esta recuperación y del posicionamiento relativo más favorable de Portoviejo en el sistema regional de ciudades ha sido la aplicación de un Plan de Ordenamiento Territorial con inclusión de una serie de directrices y determinaciones legales y una zonificación territorial no sólo de la ciudad, sino también de su entorno territorial de influencia, además de una zonificación funcional turística específica. La aplicación y seguimiento de este POT y de su zonificación general y específica se ha hecho conforme a lo establecido en el Código Orgánico de Organización Territorial, Autonomía y Descentralización de la Presidencia de la República de Ecuador (R.O.S 303 de 19 de octubre de 2010) y las competencias delegadas en el GAD del cantón de Portoviejo, que ha adoptado finalmente unas Ordenanzas propias. Y, asimismo, también esta iniciativa de ordenamiento territorial se ha hecho al amparo de la Ley de Gestión Ambiental y la Ley de Turismo, que atribuyen a los gobiernos autónomos descentralizados diversas competencias para una correcta planificación y 
gestión del territorio de acuerdo con las casuísticas y características diferenciales de sus sistemas comerciales y servicios ecosistémicos.

La zonificación funcional turística de la ciudad de Portoviejo se ha fundamentado y articulado, como no podía ser de otra manera, con el Plan de Ordenamiento Territorial del cantón Portoviejo, que delimita y determina cuatro zonas funcionales a los efectos de adecuación territorial de una serie de acciones de desarrollo socioeconómico: zona de uso sostenible, zona turística, zona residencial y zona comercial y empresarial, cada una de las cuales servirían de marco de referencia y proyección para el crecimiento urbanístico y demográfico de la ciudad sin dejar de lado la sostenibilidad de estos crecimientos y su compatibilización con la conservación y valorización del patrimonio natural y cultural preexistente. Dicha zonificación con sus directrices y ordenanzas específicas han facilitado, sin duda, una planificación del destino y una recuperación significativa tras la crisis, si bien las políticas sustantivas de desarrollo de las previsiones teóricas de estas directrices y ordenanzas no han sido precisamente proactivas y precisas, de manera que los resultados finales han sido un tanto limitados. Tan sólo tras la aprobación del Plan Estratégico de Turismo de 2017, actualmente en desarrollo, podrían paliarse estas deficiencias y concretar acciones más sustantivas y trascendentes en materia de turismo.

En cualquier caso, este estudio nos ha revelado una vez más cómo la existencia de una planificación estratégica y una gobernanza turística mínima puede garantizar una recuperación y reconstrucción de las condiciones iniciales del destino o mejorar su oferta turística y sus niveles de competitividad, y más aún si se quiere convertir el sector turístico en un catalizador de la recuperación general (Rivera y Félix, 2019). La tragedia sufrida por un desastre socionatural puede convertirse incluso en una nueva oportunidad para el desarrollo y recualificación del sector turístico superando errores del pasado. Pero, en caso contrario, de no existir una gestión eficaz y planificada, sólo se agravaría o amplificaría la crisis inicial. Por otra parte, el impacto de los desastres socio-naturales no es ni mucho menos homogéneo a nivel territorial, como se ha comprobado en la provincia de Manabí y en general a nivel regional en Ecuador, ya que unas zonas quedan más afectadas que otras, se recuperan con mayor o menor rapidez, según los casos, o incluso algunas pueden verse beneficiadas a corto plazo por la llegada de visitantes que rehúyen de las áreas más afectadas. Estas circunstancias, por tanto, condicionan los planes y medidas que se adopten en cada zona y hacen más necesaria si cabe la gestión y planificación de la crisis en un ámbito regional más o menos amplio y no meramente local o supramunicipal como se ha venido haciendo en la zona de estudio.

\section{Referencias}

Aranibar, V. (2013). Métodos de Espacialización y zonificación Turística. Universidad Mayor de San Simón, Facultad de Arquitectura y Ciencias del Hábitat, Carrera de Turismo. Cochabamba. BO

Becerra, L. y Toledo, M. (2010). El ordenamiento territorial del turismo a partir de un enfoque prospectivo. Turismo y Desarrollo Local, 3 (8), 16-29.

Brown, G., \& Raymond, C. (2014). Methods for identifying land use conflict potentialusing participatory mapping. Landscape and Urban Planning, 122, 196-208.

Brown, G.; Sanders, S., \& Reed, P. (2018). Using public participatory mapping to inform general land use planning. Landscape and Urban Planning, 177, 64-74 
Carruthers, J. I., \& Ulfarsson, G. F. (2003). Urban sprawl and the cost of public services. Environment \& Planning B Planning \& Design, 30(4), 503-522

Código Orgánico de la Producción, Comercio e Inversiones (2017). Título Preliminar, Del Objetivo y ámbito de aplicación. Quito: Gobierno de Ecuador.

Dirección Municipal de Turismo del GAD del Cantón Portoviejo (2017). Plan estratégico de turismo. Portoviejo. Ecuador: GAD Portoviejo.

Doumet, Y. y Mendoza I. (2015). Plan de manejo ecoturístico: estudio de caso en el área protegida provincial de Camarones, cantón Jama, Manabí. Revista Espamciencia, 6 (1), 47-56.

Elbeih, S., Shalaby, A. A., \& Deen, A. M. B. E. (2013). Water management problems associated with urban sprawl in giardia governorate. Egypt Using Remote Sensing and GIS, 2, 243-259.

Ewing, B. R., Pendall, R., \& Chen, D. (2010). Measuring sprawl and its transportation impacts. Transportation Research Record, 1832, 175-183.

Filion, P., \& Mcspurren, K. (2007). Smart growth and development reality: The difficult coordination of land use and transport objectives. Urban Studies, 44(3), 501-523.

Font, A. (2017). La renovación del planeamiento urbanístico. Revista científica de la Universidad de Valladolid, 17, 77-90.

Freeman, L. (2007). The effects of sprawl on neighborhood social ties: An explanatory analysis. Journal of the American Planning Association, 67(1), 69-77.

GAD de Portoviejo (2011). Plan de desarrollo y ordenamiento territorial del cantón Portoviejo. (En Línea). Portoviejo: Cantón Portoviejo. Consultado, 10 de Jun. 2016.

Haesbaert, R. (2014). Lógica zonal y ordenamiento territorial: para rediscutir la proximidad y la contigüidad espaciales. Revista Territorio y Cultura, 8 (16), 10-29.

Martin, J., Pendall, R., \& Fulton, W. (2002). Holding the line: Urban containment in the United States. Washington, D.C.: Brookings Institution.

Munton, R. (1983). London's green belt: Containment in practice. London: Routledge.

Obando, J; Ochoa, F; De Duque, R; Roza, E; Villada, I. (2014). Enfoque metodológico para la formulación de un sistema de gestión para la sostenibilidad en destinos turísticos. Anuario Turismo y Sociedad, 11, 175-200.

Orchiston, C y Highman, J. (2015). Knowledge management and tourism recovery (de)marketing: the Christchurch earthquakes 2010-2011. Revista Current Issues in Tourism, . 19, 64-84.

Organización Mundial del Turismo (OMT) (2019). Panorama del turismo internacional 2018 (Edición 2019). Madrid: OMT.

Ornés, S. (2014). La gestión urbana sostenible: conceptos, rol del gobierno local y vinculación con el marketing urbano. Provincia, 31, 147-171.

Pazmiño López, P.S. (2015). Diseño de un modelo de gestión basado en el plan estratégico para agencias de viajes y operadores de turismo. Arabato, Ecuador: Pontificia Universidad Católica de Ecuador, Trabajo fin de Master.

PNUD (Programa de las Naciones Unidas para el Desarrollo) (2014). Gestión del riego de desastres ¿Qué hace el PNUD en Gestión del Riesgo de Desastres en América Latina y el Caribe?. Washington: ONU 
Quiguengo Tituaña, I.G. (2015). Zonificación turística de los recursos y atractivos turísticos del canton San Miguel de Urcuguí. Quito, Ecuador: Universidad Central de Ecuador, Trabajo Fin de Grado en Turismo Histórico y Cultural.

Rivera Mateos, M. (Coord.) (2020). Usos sostenibles de la tierra y desarrollo humano. Sevilla: Ediciones Egregius y Universidad de Sevilla.

Rivera Mateos, M. y Félix Mendoza, A.G. (2018). La reconstrucción de destinos turísticos degradados en América Latina: Realidades y necesidades en materia de planificación turística y cooperación entre actores en la provincia de Manabí (Ecuador). En Cebrián, F., JOver, F.J. y Lois, R.C. (Coord.). América Latina en las últimas décadas: procesos y retos (pp. 1139-1154). Toledo: Universidad de Castilla-La Mancha y Asociación de Geógrafos Españoles.

Rivera Mateos, M. y Félix Mendoza, A.G. (2019). Planificación estratégica y gobernanza en la recuperación de destinos turísticos afectados por desastres socio-naturales: Un estado de la cuestión. Investigaciones Geográficas, 72: 235-254

Smith, N. (2002). New globalism, new urbanism: Gentrification as global urban strategy. Antipode, 34(3), 427-450.

Sorensen, A. (2003). The making of urban Japan: Cities and planning from Edo to the twentyfirst century. Professional Geographer, 55(2), 297-298.

Steele, E. H. (1986). Participation and rules-the functions of zoning. Law and Social Inquiry, 11(4), 709-755.

Sun, P., Tang, Y., \& Zhang, J. Q. (2011). Inspiration of urban sprawl control studies in foreign countries. Economic Geography, 31(5), 748-753.

Torres, C.; Martínez, P.; García, F. (2013). Turismo Alternativo y la zonificación para contribuir al desarrollo humano. Periplo, 20, 557 - 770.

Villegas, E; Cifuentes, A; Contreras, D; Fernández, L. (2015). Ordenamiento territorial como instrumento para la zonificación ambiental a través de la Estructura Ecológica Principal, como apoyo a la formulación de los POTs y los POMCAS en Colombia. Revista Investigación Científica y Tecnológica, 14 (2), 49-77.

Wu, C. F., Han, H. Y., \& Lai, S. G. (2009). Urban space growth management: Tools and strategies. Planners, 25(8), 15-19.

Zeng, C., Liu, Y. L., Liu, Y. F., \& Qiu, L. Q. (2013). Urban sprawl and related problems: Bibliometric analysis and refined analysis from 1991 to 2011. Chinese Geographical Science, 24(2), 245-262. 